\title{
Características agronômicas de cultivares de alho em Diamantina
}

\author{
Fábio Luiz de Oliveira ${ }^{1}$; Haroldo Doria ${ }^{1}$; Ricardo B Teodoro ${ }^{1}$; Francisco V Resende ${ }^{2}$ \\ ${ }^{1}$ UFVJM, Depto. Agronomia, R. da Glória, 187, 39100-000 Diamantina-MG; ${ }^{2}$ Embrapa Hortaliças, C. Postal 218, 70359-970 Brasília- \\ DF; fabiocapi@yahoo.com.br; ricardo.agronomia@hotmail.com; fresende@cnph.embrapa.br
}

\section{RESUMO}

Um estudo foi realizado, durante o período da safra 2007, com objetivo de avaliar as características agronômicas período de emergência das plântulas, altura de plantas, diâmetro de bulbos frescos e curados, números de bulbilhos por bulbo e produtividade comercial de quatorze cultivares de alho em Diamantina-MG. O delineamento experimental adotado foi de blocos casualizados, com quatro repetições, cujos tratamentos foram as cultivares de alho Gigante do Núcleo, Gigante de Lavínia, Gigante Roxo, Gigante Roxão, Chinês Real, Chinês São Joaquim, Cateto Roxo, Cateto Roxo (livre de vírus), Hozan, Amarante, Peruano, Caturra, Gravatá e Amarante Gouveia. As cultivares Hozan, Gigante de Lavínia, Chinês Real e Peruano apresentaram melhor desenvolvimento vegetativo inicial, com maiores valores em altura de plantas, até os 60 dias. Com relação ao número de bulbilhos/bulbo destacaram-se as cultivares Gratavá $(16,5)$, Cateto Roxo PfLv $(15,75)$, Cateto Roxo $(15,25)$ e Chinês Real $(15,25)$, diferindo das demais. A 'Gigante de Lavínia' destacou-se com a maior produtividade comercial $\left(12,61 \mathrm{t} \mathrm{ha}^{-1}\right)$, seguida pelas cultivares Gravatá $\left(10,87 \mathrm{t} \mathrm{ha}^{-1}\right)$, Chinês Real $\left(10,65 \mathrm{t} \mathrm{ha}^{-1}\right)$, Cateto Roxo Pf Lv (10,63 tha $\left.{ }^{-1}\right)$ e Caturra $\left(9,68\right.$ t ha $\left.^{-1}\right)$. AAmarante Gouveia, a cultivada na região, apresentou produtividade de $7,50 \mathrm{t} \mathrm{ha}^{-1}$, valor inferior à média nacional $\left(8,47 \mathrm{tha}^{-1}\right)$.

Palavras-chave: Allium sativum, Vale do Jequitinhonha, produtividade, cultivares.

\section{ABSTRACT Brazil \\ Agronomic characteristics of garlic cultivars in Diamantina,}

A study was carried out in Diamantina, Minas Gerais State, Brazil, during the 2007 season, to evaluate the agronomic characteristics of garlic cultivars. The experimental design was of randomized blocks, with four replications. Treatments were garlic cultivars 'Gigante do Núcleo', 'Gigante de Lavínia', 'Gigante Roxo', 'Gigante Roxão', 'Chinês Real', 'Chinês São Joaquim', 'Cateto Roxo', 'Cateto Roxo PfLv' (free of virus), 'Hozan', 'Amarante', 'Peruano', 'Caturra', 'Gravatá' and 'Amarante Gouveia'. 'Hozan', 'Gigante de Lavínia', 'Chinês Real' and 'Peruano' presented the best vegetative growth in the initial stage, with higher plant height values up to 60 days. Regarding the number of cloves/bulb, the cultivars 'Gravatá' (16.5), 'Cateto Roxo PfLv' (15.75), 'Cateto Roxo' (15.25) and 'Chinês Real' (15.25) presented higher values than the other evaluated cultivars. 'Gigante de Lavínia' presented the highest marketable yield $(12.61 \mathrm{t}$ ha-1), followed by the cultivars 'Gravatá' (10.87 tha-1), 'Chinês Real' (10.65 tha-1), 'Cateto Roxo Pf Lv' (10.63 tha-1) and 'Caturra' (9.68 t ha-1). The cultivar 'Amarante Gouveia', presented a yield of $7.50 \mathrm{t}$ ha-1, which was inferior to the national average yield ( $8.47 \mathrm{t}$ ha-1).

Keywords: Allium sativum, Jequitinhonha Valley, yield, cultivars.

(Recebido para publicação em 20 de julho de 2009; aceito em 19 de agosto de 2010) (Received on July 20; 2009; accepted on August 19, 2010)

$\mathrm{O}$ alho (Allium sativum L.) é uma das hortaliças mais importantes no Brasil, sendo utilizado na culinária regional e nacional, nas quais seu sabor e propriedade condimentar são muito apreciados. Apesar da importância da cultura no cenário nacional, atualmente o Brasil é o maior importador mundial, da ordem de cerca de 146 mil toneladas por ano, com produtos vindos principalmente da China e Argentina (ANAPA, 2008). Entretanto, a oferta do produto nacional no mercado interno tem apresentado um aumento gradativo da produção entre 2004 e 2007. O levantamento Sistemático da Produção Agrícola correspondente ao ano agrícola 2008 contabilizou uma oferta bruta de aproximadamente 91,6 mil toneladas, abaixo da média de 99,8 mil toneladas colhidas no ano anterior (CONAB, 2009).
O estado de Minas Gerais destaca-se no cenário nacional como o maior produtor de alho, com produções da ordem de 24 mil toneladas, o que corresponde a cerca de aproximadamente $27,0 \%$ da produção brasileira (IBGE, 2008). Essa hortaliça é uma importante geradora de divisas, pois possibilita a geração de grande número de empregos, sobretudo no campo, devido à elevada exigência de mão-de-obra desde a semeadura até a comercialização, possibilitando rentabilidades para grandes, médios e pequenos produtores (Vilela \& Henz, 2000).

$\mathrm{O}$ alho é uma cultura de grande importância para o Vale do Jequitinhonha, sobretudo na região do Alto Jequitinhonha, com destaque para os municípios de Gouveia e Diamantina, onde se encontra grande número de produtores, de base familiar. Estes agricultores familiares reduziram a diversidade de materiais genéticos ao uso unicamente da cultivar Amarante Gouveia. Esta cultivar vem sendo cultivada por sucessivas gerações e nos últimos anos tem se observado queda em sua produtividade, e na qualidade do alho colhido, o que estaria ligado à ocorrência de doenças viróticas, que são intensificadas e perpetuadas pelos sucessivos ciclos. Carvalho (1981) relata que, sendo a reprodução do alho por via assexuada, por meio dos bulbilhos, ocorre uma ampla disseminação de doenças, principalmente viroses, que contribuem efetivamente para a degenerescência das plantas e redução da produtividade. Assim, a busca por cultivares adaptadas às condições edafoclimáticas da região e mais resistentes à ocorrência de doenças viróticas, pode contribuir para a melhoria da produtividade da cultura na região. Nesse sentido, Resende et al. (1995), trabalhando com 
cinco clones da cultivar Gigante Roxo, selecionados por meio de cultura de meristema, e limpeza de vírus, verificaram produtividades superiores, variando de 67,2 a $114,0 \%$, quando comparados à testemunha (cultivar convencional sem limpeza de vírus).

Menezes Sobrinho et al. (1999) destacam que dentre os fatores que afetam a produção de alho em uma região deve ser considerada a diversidade de cultivares, devido à ação diferencial dos genes em condições climáticas diferentes. Segundo Trani et al. (2005) a estabilidade da produção da cultura do alho pode estar na diversidade de uso de materiais genéticos nas lavouras, pois as produtividades de diferentes cultivares de alho apresentam variações em função das condições edafoclimáticas da região e também dos tratos culturais empregados na lavoura.

Objetivou-se avaliar o comportamento de cultivares de alho nas condições edafoclimáticas do município de Diamantina, no estado de Minas Gerais.

\section{MATERIAL E MÉTODOS}

O estudo foi desenvolvido na área experimental da Universidade Federal dos Vales do Jequitinhonha e Mucuri, em Diamantina-MG (longitude 43 $36^{\prime}$ $\mathrm{W}$, latitude $18^{\circ} 15^{\prime} \mathrm{S}, 1296 \mathrm{~m}$ de altitude), na safra de 2007. Durante a condução do experimento, a precipitação média da região foi de $787,2 \mathrm{~mm}$, com média de temperaturas do ar variando de $23,1^{\circ} \mathrm{C}$ a $14,9^{\circ} \mathrm{C}$ (AGRITEMPO, 2008). O solo da área foi classificado como Neossolo Quartzarênico Órtico Típico, textura franco arenoso, cujas amostras obtidas entre $0-20 \mathrm{~cm}$ apresentaram as características químicas: $\mathrm{pH} 5,5 \mathrm{em}$ $\mathrm{CaCl}_{2} ; 13,1 \mathrm{mg} \mathrm{dm}^{-3}$ de P; $43 \mathrm{mg} \mathrm{dm}^{-3} \mathrm{de}$ $\mathrm{K} ; 1,0 \mathrm{cmol}_{\mathrm{c}} \mathrm{dm}^{-3}$ de Ca e $0,5 \mathrm{cmol}_{\mathrm{c}} \mathrm{dm}^{-3}$ de $\mathrm{Mg} ; 0,6 \mathrm{cmol}_{\mathrm{c}} \mathrm{dm}^{-3}$ de Al e saturação por bases igual a $10 \%$. Após a análise a área recebeu a aplicação de $1,0 \mathrm{t} \mathrm{ha}^{-1} \mathrm{de}$ calcário dolomítico.

O delineamento experimental adotado foi de blocos casualizados, com quatro repetições, cujos tratamentos foram as cultivares de alho Gigante do Núcleo, Gigante de Lavínia, Gigante
Roxo, Gigante Roxão, Chinês Real, Chinês São Joaquim, Cateto Roxo, Cateto Roxo (livre de vírus), Hozan, Amarante, Peruano, Caturra, Gravatá e Amarante Gouveia.

O plantio foi realizado na primeira semana de abril, sendo uma repetição em cada canteiro de 1,5 m de largura, 9,0 $\mathrm{m}$ de comprimento e $0,25 \mathrm{~m}$ de altura, adubados inicialmente com vermicomposto, na dose de $20 \mathrm{t} \mathrm{ha}^{-1}$, enriquecido com $2 \%$ de $\mathrm{P}_{2} \mathrm{O}_{5}$ (superfosfato simples) e $\mathrm{K}_{2} \mathrm{O}$ (Cloreto de potássio) e $6 \%$ de nitrogênio (sulfato de amônio). As características químicas do vermicomposto usado foram: $11,6 \mathrm{~g} \mathrm{de} \mathrm{Ng}^{-1}, 0,51 \mathrm{~g}$ de $\mathrm{P} \mathrm{kg}^{-1}, 0,94 \mathrm{~g}^{\mathrm{de}} \mathrm{K} \mathrm{kg}^{-1}, 1,76 \mathrm{~g}$ de $\mathrm{Ca} \mathrm{kg}^{-1}$ e $0,57 \mathrm{~g}$ de $\mathrm{Mg} \mathrm{kg}^{-1}$. Aos 60 dias após o plantio foi feita adubação de cobertura com esterco bovino na dose de $10 \mathrm{t} \mathrm{ha}^{-1}$. As características químicas do esterco usado foram: $11,4 \mathrm{~g}^{\mathrm{de}} \mathrm{N} \mathrm{kg}^{-1}, 0,24 \mathrm{~g}$ de $\mathrm{P} \mathrm{kg}{ }^{-1}, 1,19 \mathrm{~g}$ de $\mathrm{K} \mathrm{kg}^{-1}, 0,92 \mathrm{~g}$ de $\mathrm{Ca} \mathrm{kg}^{-1}$ e 0,34 g de $\mathrm{Mg} \mathrm{kg}^{-1}$. A irrigação foi realizada manualmente com uso de regadores, sendo os canteiros irrigados diariamente pela manhã e à tarde.

Cada parcela dos tratamentos comportou 50 plantas, espaçadas de 20 $\mathrm{cm}$ entre linhas e $10 \mathrm{~cm}$ entre plantas, sendo considerada área útil aquela compreendida pelas 20 plantas centrais de cada parcela. Na primeira repetição foram semeados os bulbilhos-semente da segunda geração classificados como graúdos (peso médio de $4 \mathrm{~g}$ ), na segunda os médios (peso médio de $3 \mathrm{~g}$ ), na terceira os pequenos (peso médio de $2 \mathrm{~g}$ ) e na quarta uma mistura das três classes de bulbilhos-semente.

Avaliou-se o período de emergência das plântulas, altura das plantas (cm) e o diâmetro dos bulbos ( $\mathrm{mm}$ ) em formação, aos 60, 90 e 120 dias após o plantio. Aos 150 dias foi feita a colheita de todas as cultivares, quando se avaliou a massa total dos bulbos frescos $\left(\mathrm{g} \mathrm{m}^{-2}\right)$. Após um período de cura de 20 dias, avaliou-se a massa total de bulbos curados $\left(\mathrm{g} \mathrm{m}^{-2}\right)$, diâmetro ( $\mathrm{mm})$ e massa média individual dos bulbos curados $(\mathrm{g})$, número de bulbilhos por bulbo e a produtividade comercial $\left(\mathrm{t} \mathrm{ha}^{-1}\right)$.

Os dados foram submetidos à análise de variância e para aqueles com significância, aplicou-se o teste de Scott-Knott a $5 \%$ de probabilidade para a compara- ção das médias.

\section{RESULTADOS E DISCUSSÃO}

Não houve diferença significativa para o tempo de emergência de plântulas entre as cultivares estudadas, sendo que todas apresentaram em torno de $80 \%$ de emergência aos 24 dias depois do plantio.

Observou-se que as plantas apresentaram diferenças significativas para altura das plantas aos 60 dias após o plantio, e não havendo diferenças aos 90 e 120 dias (Tabela 1). As cultivares Cateto Roxo, Amarante Gouveia, Gravatá, Cateto Roxo PfLv, Gigante Roxo, Chinês São Joaquim, Caturra, Amarante, Gigante Roxão e Gigante do Núcleo apresentaram menor altura quando avaliadas aos 60 dias após plantio com alturas entre 23,7 e $27,0 \mathrm{~cm}$. Aos 90 e 120 dias a diferença não mais existiu, quando, segundo Resende et al. (1999), é a fase de crescimento intenso das plantas e essas tendem a apresentar maiores investimentos no acúmulo de reservas nos bulbos. Ferreira (1972) relata que esse período pode se estender até os 120 dias, dependendo da cultivar e das condições edafoclimáticas.

As cultivares Hozan, Gigante de Lavínia, Chinês Real e Peruano apresentaram melhor desenvolvimento vegetativo inicial, com maiores valores em altura das plantas, até os 60 dias, quando comparada a algumas cultivares (Tabela 1); no entanto aos 90 dias essa diferença praticamente deixou de existir, demonstrando uma possível equiparação entre as cultivares na fase de intenso desenvolvimento vegetativo. Esse resultado corrobora com os estudos realizado por Menezes Sobrinho et al. (1999), que avaliaram diferentes genótipos por meio de agrupamento destes, onde também observaram superioridade para a cultivar Hozan em relação a outras cultivares, apenas nessa fase inicial. Resultados diferentes foram obtidos por Mota et al. (2005) observando maiores alturas para as cultivares Gigante Roxo $(63,4 \mathrm{~cm})$, Cateto Roxo (61,8 cm) e Amarante (66,8 $\mathrm{cm})$ aos 70 dias de plantio.

As plantas apresentaram diferença significativa para o diâmetro dos bul- 
Tabela 1. Altura das plantas e diâmetros dos bulbos em formação de cultivares de alho (plant height and bulb diameter of garlic cultivars). Diamantina, UFVJM, 2007.

\begin{tabular}{lcccccc}
\hline \multirow{2}{*}{ Cultivares } & \multicolumn{3}{c}{ Altura das plantas (cm) } & \multicolumn{3}{c}{ Diâmetro do bulbo (mm) } \\
\cline { 2 - 6 } & $\mathbf{6 0}^{\mathbf{1}}$ & $\mathbf{9 0}$ & $\mathbf{1 2 0}$ & $\mathbf{6 0}$ & $\mathbf{9 0}$ & $\mathbf{1 2 0}$ \\
\hline Gigante do Núcleo & $27,0 \mathrm{~b}^{2}$ & $39,2 \mathrm{a}$ & $40,2 \mathrm{a}$ & $18,5 \mathrm{~b}$ & $27,2 \mathrm{~b}$ & $43,0 \mathrm{a}$ \\
Gigante de Lavínia & $29,2 \mathrm{a}$ & $36,5 \mathrm{a}$ & $32,0 \mathrm{a}$ & $23,0 \mathrm{a}$ & $27,2 \mathrm{~b}$ & $42,5 \mathrm{a}$ \\
Gigante Roxo & $25,2 \mathrm{~b}$ & $36,0 \mathrm{a}$ & $50,0 \mathrm{a}$ & $17,0 \mathrm{~b}$ & $24,2 \mathrm{~b}$ & $40,0 \mathrm{~b}$ \\
Gigante Roxão & $26,7 \mathrm{~b}$ & $41,2 \mathrm{a}$ & $47,0 \mathrm{a}$ & $25,5 \mathrm{a}$ & $31,5 \mathrm{~b}$ & $40,2 \mathrm{~b}$ \\
Chinês Real & $29,2 \mathrm{a}$ & $43,2 \mathrm{a}$ & $46,2 \mathrm{a}$ & $23,0 \mathrm{a}$ & $35,7 \mathrm{a}$ & $46,0 \mathrm{a}$ \\
Chinês S. Joaquim & $25,7 \mathrm{~b}$ & $39,0 \mathrm{a}$ & $45,5 \mathrm{a}$ & $22,5 \mathrm{a}$ & $30,0 \mathrm{~b}$ & $42,2 \mathrm{a}$ \\
Cateto Roxo & $23,7 \mathrm{~b}$ & $31,2 \mathrm{a}$ & $40,0 \mathrm{a}$ & $22,0 \mathrm{a}$ & $30,5 \mathrm{~b}$ & $39,5 \mathrm{~b}$ \\
Cateto Roxo PfLv & $25,0 \mathrm{~b}$ & $45,5 \mathrm{a}$ & $41,5 \mathrm{a}$ & $23,5 \mathrm{a}$ & $37,5 \mathrm{a}$ & $44,7 \mathrm{a}$ \\
Hozan & $34,5 \mathrm{a}$ & $43,2 \mathrm{a}$ & $44,0 \mathrm{a}$ & $25,5 \mathrm{a}$ & $28,5 \mathrm{~b}$ & $40,2 \mathrm{~b}$ \\
Amarante & $26,7 \mathrm{~b}$ & $38,0 \mathrm{a}$ & $46,5 \mathrm{a}$ & $23,0 \mathrm{a}$ & $30,0 \mathrm{~b}$ & $42,2 \mathrm{a}$ \\
Peruano & $31,5 \mathrm{a}$ & $36,0 \mathrm{a}$ & $39,7 \mathrm{a}$ & $23,2 \mathrm{a}$ & $28,0 \mathrm{~b}$ & $36,7 \mathrm{~b}$ \\
Caturra & $25,7 \mathrm{~b}$ & $39,2 \mathrm{a}$ & $44,0 \mathrm{a}$ & $23,7 \mathrm{a}$ & $30,7 \mathrm{~b}$ & $38,2 \mathrm{~b}$ \\
Gravatáy & $24,7 \mathrm{~b}$ & $38,7 \mathrm{a}$ & $42,7 \mathrm{a}$ & $23,7 \mathrm{a}$ & $27,7 \mathrm{~b}$ & $44,0 \mathrm{a}$ \\
Amarante Gouveia & $24,0 \mathrm{~b}$ & $39,7 \mathrm{a}$ & $44,7 \mathrm{a}$ & $22,0 \mathrm{a}$ & $33,7 \mathrm{a}$ & $47,2 \mathrm{a}$ \\
\hline \multicolumn{1}{c}{ CV (\%) } & 13,06 & 11,66 & 10,46 & 11,79 & 13,91 & 9,27 \\
\hline
\end{tabular}

${ }^{1}$ Dias após o plantio. ${ }^{2}$ Médias seguidas de mesma letra nas colunas não diferem estatisticamente entre si, Teste Scott-Knott, $\mathrm{p}<0,05$ (means followed by the same letter in the column do not differ from each other, Scott-Knott's test, $\mathrm{p}<0,05$ ).

bos em formação aos 60, 90 e 120 dias após o plantio. Pelos resultados obtidos percebe-se que algumas cultivares iniciam o investimento em bulbificação mais precocemente que outras, com exceção das cultivares Gigante do Núcleo e Gigante Roxo que apresentaram os menores diâmetros em relação à maioria das cultivares. Aos 90 dias observa-se que muitas cultivares já apresentavam diâmetros semelhantes estatisticamente, com destaque para algumas cultivares como Chinês Real, Cateto Roxo PfLv e Amarante Gouveia. Esses resultados podem ser reflexos da priorização das plantas em investir na formação dos bulbos, já que cultivares como Cateto Roxo PfLv e Amarante Gouveia estavam aumentando o diâmetro do bulbo e investindo na altura das plantas mais tardiamente. Este fato levaria as cultivares a ter diâmetros de bulbos estatisticamente superiores à maioria; entretanto, a cultivar Chinês Real consegue se destacar tanto na altura das plantas como no diâmetro do bulbo (Tabela 1).

Contudo aos 120 dias a maioria das cultivares se destacaram com relação ao diâmetro do bulbo, exceto a Gigante Roxo, Gigante Roxão, Cateto Roxo, Peruano, Caturra e Hozan que apresen- taram valores estatisticamente inferiores às demais.

É valido ressaltar que estas diferenças no desenvolvimento inicial das cultivares podem ter ocorrido devido às características genéticas dos materiais, mas também em função da propagação convencional. Esta propagação incorre no uso de bulbilhos-semente que podem estar em estado de maturação fisiológica diferenciada, além de outros fatores como fotoperíodo, temperatura, altitude elevada, fertilidade do solo e manejo da irrigação, que podem interferir no desenvolvimento das cultivares.

Houve diferenças significativas para a massa e o número de bulbilhos por bulbo, não se observando diferenças para o diâmetro médio do bulbo curado (Tabela 2). Os resultados, com relação à massa média dos bulbos curados, demonstram que as cultivares Gigante de Lavínia, Chinês Real, Cateto Roxo PfLv, Caturra e Gravatá apresentaram superioridade sobre as demais. Esses resultados se aproximam dos encontrados por Trevisan et al. (1997) para a cultivar Gigante de Lavínia de 27,47 g para os bulbos curados e mais de $45 \%$ dos bulbos curados entre 35 e $45 \mathrm{~mm}$ de diâmetro, trabalhando nas condições de Santa Maria-RS. No entanto Resende et al. (2003), trabalhando com algumas dessas cultivares em Lavras-MG encontraram valores superiores, com as cultivares apresentando em torno de 29,75 g e $45,83 \%$ dos bulbos entre 47 e $55 \mathrm{~mm}$ e apenas $6,35 \%$ com 37 a $42 \mathrm{~mm}$. De acordo com Mota (2003), essas diferenças normalmente ocorrem em função das variações nas condições edafoclimáticas em que os materiais foram cultivados.

Com relação ao número de bulbilhos/bulbo observa-se que a Gravatá, Cateto Roxo PfLv, Cateto Roxo e Chinês Real apresentam os maiores valores, diferindo das outras cultivares (Tabela 2). Resende et al. (1999) observaram valores maiores com a cultivar Gigante Roxão, 22,25 bulbilhos quando trabalhando com material oriundo de cultura de tecidos, e 16,25 quando a planta era oriunda de multiplicação convencional. Já Resende (1997), em avaliações de algumas cultivares em Porteirinha-MG, observou valores para a cultivar Gigante Roxão de 16,37 bulbilhos. Resende et al. (2003), trabalhando em condições do município de Lavras-MG, verificaram valores um pouco superiores, para as cultivares Amarante (12,09), Gigante de Lavínia $(18,27)$ e Gigante Roxo $(17,22)$. No entanto, Corrêa et al. (2003) encon- 
Tabela 2. Massa e diâmetro médio do bulbo curado e número de bulbilhos por bulbo de cultivares de alho (diameter and weight of dehydrated bulb and number of cloves per bulb of garlic cultivars). Diamantina, UFVJM, 2007.

\begin{tabular}{lccc}
\hline Cultivares & $\begin{array}{c}\text { Massa média dos } \\
\text { bulbos curados } \\
\mathbf{( g )}\end{array}$ & $\begin{array}{c}\text { Diâmetro médio dos } \\
\text { bulbos curados } \\
\mathbf{( m m})\end{array}$ & $\begin{array}{c}\text { Número de } \\
\text { bulbilhos por } \\
\text { bulbo }\end{array}$ \\
\hline Gigante do Núcleo & $15,61 \mathrm{~b}^{1}$ & $36,75 \mathrm{a}$ & $13,00 \mathrm{~b}$ \\
Gigante de Lavínia & $25,22 \mathrm{a}$ & $39,75 \mathrm{a}$ & $12,75 \mathrm{~b}$ \\
Gigante Roxo & $16,05 \mathrm{~b}$ & $36,00 \mathrm{a}$ & $10,25 \mathrm{~b}$ \\
Gigante Roxão & $17,20 \mathrm{~b}$ & $33,50 \mathrm{a}$ & $9,25 \mathrm{~b}$ \\
Chinês Real & $21,31 \mathrm{a}$ & $38,75 \mathrm{a}$ & $15,25 \mathrm{a}$ \\
Chinês São Joaquim & $15,21 \mathrm{~b}$ & $32,50 \mathrm{a}$ & $10,25 \mathrm{~b}$ \\
Cateto Roxo & $16,81 \mathrm{~b}$ & $35,25 \mathrm{a}$ & $15,25 \mathrm{a}$ \\
Cateto Roxo Pf Lv & $21,27 \mathrm{a}$ & $37,50 \mathrm{a}$ & $15,75 \mathrm{a}$ \\
Hozan & $12,61 \mathrm{~b}$ & $31,50 \mathrm{a}$ & $11,00 \mathrm{~b}$ \\
Amarante & $16,11 \mathrm{~b}$ & $36,25 \mathrm{a}$ & $10,75 \mathrm{~b}$ \\
Peruano & $10,75 \mathrm{~b}$ & $32,50 \mathrm{a}$ & $10,25 \mathrm{~b}$ \\
Caturra & $19,37 \mathrm{a}$ & $34,00 \mathrm{a}$ & $11,00 \mathrm{~b}$ \\
Gravatá & $21,74 \mathrm{a}$ & $36,50 \mathrm{a}$ & $16,50 \mathrm{a}$ \\
Amarante Gouveia & $15,01 \mathrm{~b}$ & $39,50 \mathrm{a}$ & $12,75 \mathrm{~b}$ \\
\hline \multicolumn{1}{c}{ CV (\%) } & 24,73 & 14,06 & 21,21 \\
\hline
\end{tabular}

${ }^{1}$ Médias seguidas de mesma letra nas colunas não diferem estatisticamente entre si, Teste Scott-Knott, $\mathrm{p}<0,05$ (means followed by the same letter in the column do not differ from each other, Scott-Knott's test, $\mathrm{p}<0,05)$.

Tabela 3. Massa total de bulbos frescos e curados e produtividade comercial de cultivares de alho (total weight of fresh and dehydrated bulbs and marketable yield of garlic cultivars). Diamantina, UFVJM, 2007.

\begin{tabular}{|c|c|c|c|}
\hline Cultivares & $\begin{array}{c}\text { Massa total de } \\
\text { bulbos frescos } \\
\qquad\left(\mathrm{g} \mathrm{m}^{-2}\right)\end{array}$ & $\begin{array}{l}\text { Massa total de } \\
\text { bulbos curados } \\
\qquad\left(\mathrm{g} \mathrm{m}^{-2}\right)\end{array}$ & $\begin{array}{c}\text { Produtividade } \\
\text { comercial } \\
\left(\mathbf{t ~ h a}^{-1}\right)\end{array}$ \\
\hline Gigante do Núcleo & $431,80 \mathrm{a}^{1}$ & $312,23 \mathrm{~b}$ & $7,80 \mathrm{~b}$ \\
\hline Gigante de Lavínia & $689,46 \mathrm{a}$ & $504,43 \mathrm{a}$ & $12,61 \mathrm{a}$ \\
\hline Gigante Roxo & $466,80 \mathrm{a}$ & $321,16 \mathrm{~b}$ & $8,02 \mathrm{~b}$ \\
\hline Gigante Roxão & $527,50 \mathrm{a}$ & $344,13 \mathrm{~b}$ & $8,60 \mathrm{~b}$ \\
\hline Chinês Real & $563,15 \mathrm{a}$ & $426,20 \mathrm{a}$ & $10,65 \mathrm{a}$ \\
\hline Chinês São Joaquim & $444,32 \mathrm{a}$ & $304,30 \mathrm{~b}$ & $7,60 \mathrm{~b}$ \\
\hline Cateto Roxo & $470,00 \mathrm{a}$ & $336,25 \mathrm{~b}$ & $8,40 \mathrm{~b}$ \\
\hline Cateto Roxo Pf Lv & $572,42 \mathrm{a}$ & $425,52 \mathrm{a}$ & $10,63 \mathrm{a}$ \\
\hline Hozan & $403,22 \mathrm{a}$ & $252,30 \mathrm{~b}$ & $6,30 \mathrm{~b}$ \\
\hline Amarante & $492,07 \mathrm{a}$ & $322,32 \mathrm{~b}$ & $8,05 \mathrm{~b}$ \\
\hline Peruano & $333,37 \mathrm{a}$ & $215,17 \mathrm{~b}$ & $5,37 \mathrm{~b}$ \\
\hline Caturra & $574,44 \mathrm{a}$ & $387,55 \mathrm{a}$ & $9,68 \mathrm{a}$ \\
\hline Gravatá & $602,25 \mathrm{a}$ & $434,90 \mathrm{a}$ & $10,87 \mathrm{a}$ \\
\hline Amarante Gouveia & $446,60 \mathrm{a}$ & $300,27 \mathrm{~b}$ & $7,50 \mathrm{~b}$ \\
\hline $\mathrm{CV}(\%)$ & 31,93 & 24,72 & 24,77 \\
\hline
\end{tabular}

${ }^{1}$ Médias seguidas de mesma letra nas colunas não diferem estatisticamente entre si, Teste Scott-Knott, $\mathrm{p}<0,05$ (means followed by the same letter in the column do not differ from each other, Scott-Knott's test, $\mathrm{p}<0,05)$. traram valores inferiores para a cultivar Gravatá $(11,45)$ e Souza \& Macedo (2003) para a cultivar Gigante do Núcleo $(8,00)$. Estes resultados reforçam a afirmação de que as cultivares apresentam diferenças em seu comportamento em função dos fatores edafoclimáticos a que elas são submetidas, conforme discutido por Menezes Sobrinho et al. (1999). Isso levanta a possibilidade dos produtores do município trabalharem com outras cultivares de alho, que nesse ensaio apresentaram resultados tão bons quanto o material genético já usado, o que aumentaria a diversidade genética local, promovendo a redução de viroses e por conseqüência maior estabilidade produtiva na região.

Não houve diferenças significativas entre as cultivares para a massa total de bulbos frescos colhidos por unidade de área. No entanto, após o período de 20 dias de cura, sob as condições do mês de outubro, em Diamantina, notou-se diferenças para a massa total de bulbos curados e por conseqüência na produtividade comercial (Tabela 3 ). A diferença entre as cultivares para a massa total dos bulbos curados está ligada à diferença na queda de peso apresentada pelos bulbos durante o período de cura. Por exemplo, a cultivar Gigante de Lavínia apresentou queda de $26 \%$ no peso total de bulbos, enquanto a cultivar Peruano apresentou $35 \%$ e a Amarante Gouveia 32\%. Esse resultado demonstra que as cultivares apresentam comportamentos diferentes quanto a perda de água durante o período de cura, e por isso podem necessitar de períodos diferenciados de colheita e cura para alcançarem uma estabilidade de peso para a comercialização. Oliveira et al. (2004) observaram que a época de colheita interfere nos resultados de perda de massa ao final do armazenamento pois, à medida em que se colheu bulbos mais desenvolvidos, em estádio avançado de maturação, as perdas foram reduzidas, apresentando os bulbos colhidos aos 162 dias as menores perdas em relação aos colhidos semanalmente a partir de 132 dias após plantio.

Após o período de cura, observou-se que a cultivar Gigante de Lavínia (12,61 $\mathrm{t} \mathrm{ha}^{-1}$ ) apresentou a maior produtividade comercial, mas não diferiu das cultivares Gravatá, Chinês Real, Cateto Roxo PF 
Lv e Caturra. Salienta-se que a cultivar Amarante Gouveia classificou-se no grupo que apresentou as produtividades mais baixas (Tabela 3). Em alguns trabalhos foram identificadas produtividades para a cultivar Gigante de Lavínia, próximas às observadas nesse estudo: Oliveira (1999) com 11,11 tha-1, Oliveira et al. (2003) com 10,24 t ha-1. Em outros trabalhos foram observadas produtividades inferiores, como nos estudos de Resende (1997) com 7,94 t $\mathrm{ha}^{-1}$, Trevisan et al. (1997) com 8,71 t $\mathrm{ha}^{-1}$ e Silva et al. (2001), com 8,37 t ha-1. Quanto às demais cultivares, os resultados observados foram superiores aos encontrados por alguns autores, como Mota (2003) para as cultivares Gravatá e Gigante Roxão e Trani et al. (2005) para a cultivar Cateto Roxo. Outros apresentaram resultados semelhantes como os observado por Trani et al. (2005), que também observaram as menores produtividades com a cultivar Peruano $\left(5,7 \mathrm{t} \mathrm{ha}^{-1}\right)$, trabalhando no município de Campinas-SP.

Vale ressaltar que muitas das cultivares estudadas apresentaram produtividade comercial, estatisticamente igual à Amarante Gouveia, e produções inferiores à média nacional da última safra, que foi de 8,47 tha-1 (IBGE, 2008). Além da Gigante de Lavínia, podem ser destacadas as cultivares Gravatá $(10,87$ t ha $\left.{ }^{-1}\right)$, Chinês Real $\left(10,65\right.$ t ha $\left.^{-1}\right)$, Cateto Roxo PfLv (10,63 tha-1) e Caturra (9,68 $\left.\mathrm{t} \mathrm{ha}^{-1}\right)$. Com base nos resultados obtidos, as cultivares estudadas aumentam a possibilidade de adoção de novas cultivares pelos produtores de Diamantina, o que aumentaria a diversidade genética local, contribuindo para a estabilidade produtiva na região.

\section{AGRADECIMENTOS}

Os autores agradecem à FAPEMIG, UFVJM e Embrapa Hortaliças pelas contribuições indispensáveis para realização deste trabalho.

\section{REFERÊNCIAS}

AGRITEMPO. Disponível em: www.agritempo. gov.br/agroclima/sumario. Acessado em $25 \mathrm{de}$ agosto de 2008.

ANAPA. Importação de Alho no Brasil 2008. Disponível em: www.anapa.com.br/.../ importacoes-de-alho-no-brasil-2008.pdf Acessado em 20 de novembro de 2009.

CARVALHO MG. 1981. Viroses do alho. Fitopatologia Brasileira 6: 299-300.

CONAB. Alho: balanço de oferta e demanda e produção no Brasil. Disponível em: www. anapa.com.br/principalimages/stories/ alhojulho2009.pdf. Acessado em: 20 de novembro de 2009.

CORRÊA TM; PALUDO SK; RESENDE FV; OLIVEIRA PSR. 2003. Adubação química e cobertura morta em alho proveniente de cultura de tecidos. Horticultura Brasileira 21: 601-604.

FERREIRA FA. 1972. Análise do crescimento de quatro cultivares de alho (Allium sativum L.). Viçosa: UFV. 41 p (Tese mestrado).

IBGE. Sistema IBGE de recuperação automática - SIDRA; Disponível em: www.sidra.ibge. gov.br/bda/tabela/listabl.asp?c=1612\#nota. Acessado em 25 de agosto de 2008.

MENEZES SOBRINHO JA; CHARCHAR JM; ARAGÃO FAS. 1999. Caracterização morfológica de germoplasma de alho por análises multivariada, componentes principais e variáveis canônicas. Horticultura Brasileira 17: 96-101.

MOTA JH. 2003. Diversidade Genética e Características Morfológicas Físico-Quimicas e Produtivas de Cultivares de Allium sativum L. Lavras: UFLA. 49p (Tese doutorado).

MOTA JH; SOUZA RJ; REZENDE GM; TEIXEIRA IR. 2005. Similaridade morforlógica de cultivares de alho (Allium sativum L.). Revista Científica Eletrônica de Agronomia. Disponível em: www.revista. inf.br/agro08/. Acessado em 15 de dezembro de 2008.

OLIVEIRA CM. 1999. Determinação do ponto de colheita em cultivares de alho. Lavras: UFLA. $51 \mathrm{p}$ (Tese mestrado).
OLIVEIRA CM; SOUZA RJ; YURI JE; MOTA JH; RESENDE GM. 2003. Determinação do ponto de colheita na produção de alho. Horticultura Brasileira 21: 506-509.

OLIVEIRA CM; SOUZA RJ; MOTA JH; YURI JE; RESENDE GM. 2004. Época de colheita e potencial de armazenamento em cultivares de alho. Determinação do ponto de colheita na produção de alho. Horticultura Brasileira 22: 804-807.

RESENDE FV; SOUZA RJ; FAQUIN V; RESENDE JTV. 1999. Comparação do crescimento e produção entre alho proveniente de cultura de tecidos e de multiplicação convencional. Horticultura Brasileira 17: 118-124.

RESENDE FV; SOUZA RJ; PASQUAL M. 1995. Comportamento em condições de campo de clones de alho obtidos por cultura de meristema. Horticultura Brasileira 13: 44-46.

RESENDE GM. 1997. Desempenho de cultivares de alho no norte de Minas Gerais. Horticultura Brasileira 15: 127- 130.

RESENDE GM; CHAGAS SJR; PEREIRA LV. 2003. Características produtivas e qualitativas de cultivares de alho. Horticultura Brasileira 21: 686-689.

SILVA EC; SOUZA RJ; SANTOS VS. 2001. Efeito do método de multiplicação na produção e no armazenamento de cultivares de alho. Ciência Agrotécnica 25: 281-287.

SOUZA RJ; MACEDO FS. 2003. Produção e qualidade de cultivares de alho catarinenses, submetidas à vernalização, na região de Lavras-MG. In: CONGRESSO BRASILEIRO DE OLERICULTURA, 43. Resumos... Recife: SOB (CD-ROM).

TRANI PE; PASSOS FA; FOLTRAN DE; TIVELLI SW; RIBEIRO IJA. 2005. Avaliação dos acessos de alho pertencentes à coleção do Instituto Agronômico de Campinas. Horticultura Brasileira 23: 935-939.

TREVISAN JN; MARTINS GA; SANTOS NRZ. 1997. Influência da época de plantio na produção de classes de bulbos comerciais de cultivares de alho (Allium sativum L.). Ciência Rural 27: 7-11.

VILELA NJ; HENZ GP. 2000. Situação atual da participação das hortaliças no agronegócio brasileiro e perspectivas futuras. Cadernos de Ciência \& Tecnologia 17: 71-89. 